\title{
Yurii Vasil'evich Shmartsev (Dedicated to his 80th birthday)
}

DOI: $10.1134 / \mathrm{S} 106378261012016 \mathrm{X}$

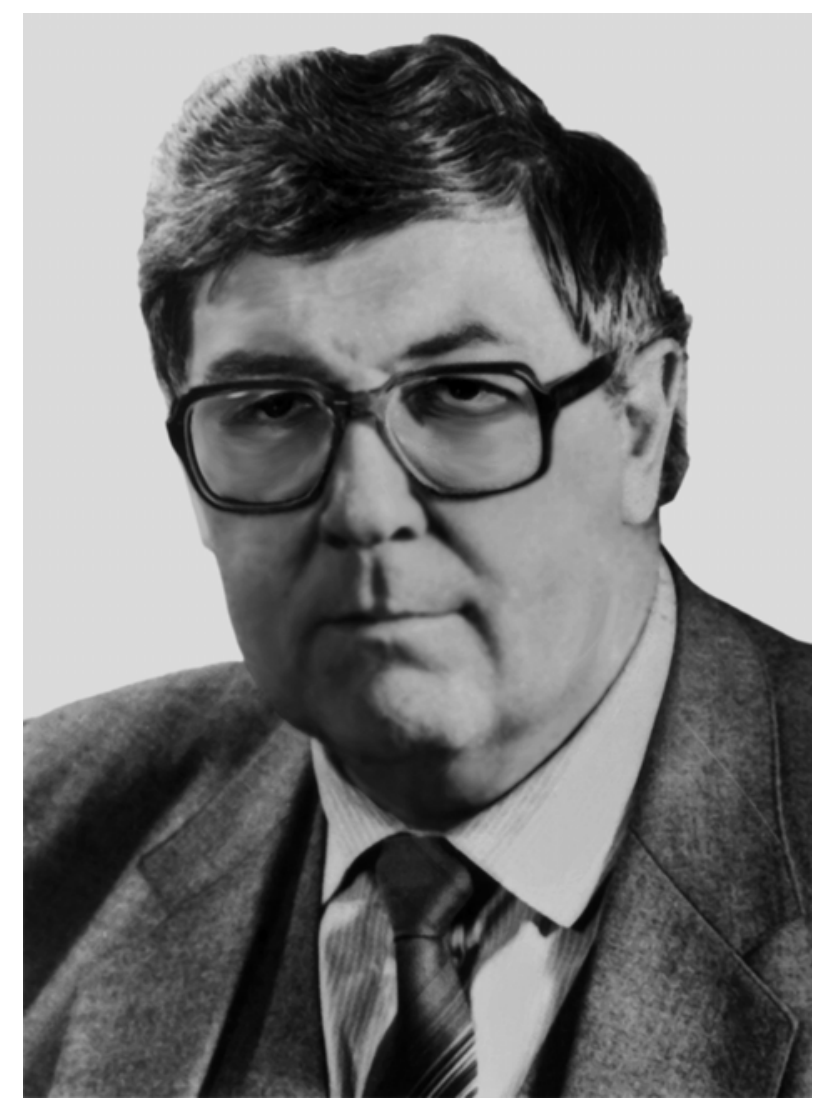

This year, Yurii Vasil'evich Shmartsev would have been 80 . We remember Shmartsev as a great authority in the field of impurity centers in semiconductors, as a scientist with an active attitude in life, and as a mentor of young scientists.

For more than 30 years, Shmartsev's scientific work was inseparably linked with the Ioffe Physical Technical Institute (Russian Academy of Sciences), where he was directly involved in the initiation and development of new areas in the physics of semiconductors, such as isovalent doping of III-V binary compounds, kinetic phenomena in heavily doped semiconductors, physical processes in a two-dimensional electron gas, and so on. It is also worth noting that Shmartsev did not restrict himself only to the theoretical and experimental aspects of the problems under consideration, but was always interested in technological and applied issues, trying to find a practical application for knowledge obtained. In 1987, he and his colleagues were honored with a Soviet State Prize for a series of studies concerned with isovalent doping of binary semiconductors.

It is especially noteworthy that, from the very date of the founding of the journal Fizika i Tekhnika Poluprovodnikov in 1967, Shmartsev was involved in this journal as its deputy editor-in-chief. He was responsible for solution of practical issues related to the editorial portfolio and communication with reviewers and scientific editors. Due to the combined efforts of the editor-in-chief and Shmartsev, the journal became a prestigious specialized scientific monthly, not only in this country but also abroad.

The scientific-organizational activity of Shmartsev was multifaceted and included involvement in the work of the Bureau of the Scientific Council Physics and Chemistry of Semiconductors at the Presidium of the Academy of Sciences and in the work of scientific and specialized councils at the Ioffe Physical Technical Institute of the Russian Academy of Sciences and at St. Petersburg State Polytechnical University. Of course, we cannot exclude mentioning his prominent pedagogical work as a brilliant lector and mentor of young scientific specialists. Many of Shmartsev's students are working in our country and abroad in various fields of physics and the technology of semiconductors.

Shmartsev was and remains for us a vivid example of a scientist and an intellectual, the fond memory of whom will remain for a long time in our hearts.

The editorial staff of the Fizika i Tekhnika Poluprovodnikov, students, colleagues, and friends

Translated by A. Spitsyn 